ARTICLE

\title{
The chemistry of branched condensed phosphates
}

\author{
Tobias Dürr-Mayer', Danye Qiu (1) 1, Verena B. Eisenbeis (10 1, Nicole Steck (10 1, Markus Häner (1) 1, \\ Alexandre Hofer (1) ${ }^{2}$, Andreas Mayer (10 ${ }^{3}$, Jay S. Siegel (1) ${ }^{4,5}$, Kim K. Baldridge ${ }^{4}$ \& Henning J. Jessen (1) ${ }^{1,5,6 \times}$
}

Condensed phosphates may exist as linear, cyclic or branched structures. Due to their important role in nature, linear polyphosphates have been well studied. In contrast, branched phosphates (ultraphosphates) remain largely uncharacterised, because they were already described in 1950 as exceedingly unstable in the presence of water, epitomized in the antibranching-rule. This rule lacks experimental backup, since, to the best of our knowledge, no rational synthesis of defined ultraphosphates is known. Consequently, detailed studies of their chemical properties, reactivity and potential biological relevance remain elusive. Here, we introduce a general synthesis of monodisperse ultraphosphates. Hydrolysis half-lives up to days call the antibranching-rule into question. We provide evidence for the interaction of an enzyme with ultraphosphates and discover a rearrangement linearizing the branched structure. Moreover, ultraphosphate can phosphorylate nucleophiles such as amino acids and nucleosides with implications for prebiotic chemistry. Our results provide an entry point into the uncharted territory of branched condensed phosphates.

\footnotetext{
${ }^{1}$ Institute of Organic Chemistry, University of Freiburg, Freiburg, Germany. ${ }^{2}$ Department of Chemistry, University of Cambridge, Cambridge, United Kingdom ${ }^{3}$ Département de Biochimie, Université de Lausanne, Epalinges, Switzerland. ${ }^{4}$ Health Science Platform, Tianjin University, Tianjin, P R China. ${ }^{5}$ Freiburg Research Institute for Advanced Studies, University of Freiburg, Freiburg, Germany. ${ }^{6}$ Cluster of Excellence livMatS @ FIT - Freiburg Center for Interactive Materials and Bioinspired Technologies, University of Freiburg, Freiburg, Germany. ${ }^{凶}$ email: henning.jessen@oc.uni-freiburg.de
} 
P olyphosphates (polyP) are polymers of orthophosphate linked by phosphoanhydride bonds. They are ubiquitous in living organisms with numerous biological functions ${ }^{1}$. PolyP may exist in three principally different structures (see Fig. 1a): linear, cyclic (metaphosphates) or branched (ultraphosphates) $)^{2}$. Cellular polyP are now defined as exclusively linear polymers ${ }^{1,3-5}$. This paradigm evolved, despite early reports on the presence of metaphosphates in cellular extracts ${ }^{6-8}$ and was recently called into question by ${ }^{31} \mathrm{P}$ solid-state NMR data from whole Xanthobacter autotrophicus ${ }^{9}$. There have only been scattered comments on ultraphosphates in biology 3,10 . These, in turn, dismiss the occurrence of ultraphosphates by referring to the antibranching-rule, which was coined in 1950 and has persisted since then ${ }^{11-15}$. Some work has been done on vitreous and crystalline ultraphosphates ${ }^{16-22}$ owing to applications as laser materials (see Fig. 1b) ${ }^{11,23}$. Yet, studies on monodisperse ultraphosphates are limited. In the 1970s, Glonek reported cyclic ultraphosphate structures from condensations of ortho- or metaphosphates (see Fig. 1c) ${ }^{24-28}$. The ultraphosphates could neither be obtained in pure form nor isolated and in part lack unambiguous analytical proof. The addition of water resulted in the instantaneous hydrolysis of the branches ${ }^{24}$.

In recent years, branched oligophosphates caught attention again: cyclic ultraphosphates like $\mathbf{1 1}$ with modifications on the terminal phosphate can now be obtained and applied in the syntheses of linear nucleoside, dinucleoside and inorganic poly $\mathrm{P}^{29-33}$. Cummins et al. synthesised 7 as its [PPN] (bis(triphenylphosphine)iminium) salt, which allowed the isolation of the product ${ }^{34}$. Application of 7 was demonstrated in the tetraphosphorylation of nucleotides and enabled the synthesis of another ultraphosphate species containing four phosphates in the cyclic subunit ${ }^{35}$. Although cyclic ultraphosphates have thus recently become accessible, there is no synthesis of ultraphosphates available that are devoid of cyclic substructures and therefore are true constitutional isomers of linear poly $\mathrm{P}^{36}$. This fundamental type of condensed phosphates remained unstudied.

Here, we report the synthesis of non-cyclic ultraphosphates using phosphoramidite chemistry. This approach provides access to both symmetrically modified ultraphosphates containing three equal modifications on each terminal phosphate, including the smallest possible unmodified ultraphosphate $\mathrm{uP}_{4}(2)$ as well as unsymmetrical analogues containing two different residues. The synthetic approach enables the generation of thio- and selenoultraphosphates. To interrogate the antibranching-rule, we report hydrolysis studies including enzymatic degradation. Furthermore, we show the phosphorylation of nucleosides with inorganic ultraphosphate with implications for prebiotic chemistry (see Fig. 1d). We also study the reactivity of modified ultraphosphates in organic solvent by using a combination of ${ }^{31} \mathrm{P}-\mathrm{NMR}$ and capillary electrophoresis mass spectrometry (CE-MS) and discover an ultraphosphate rearrangement, which we name the phosphate walk.

\section{Results}

Symmetrical ultraphosphates. Phosphordiamidites are used in linear polyP syntheses by twofold activation and reaction with (modified) phosphates ${ }^{37}$. A phosphortriamidite should therefore enable threefold activation and reaction with three phosphates to produce a mixed $\mathrm{P}(\mathrm{III})-\mathrm{P}(\mathrm{V})$-anhydride intermediate 18 (hereafter, called ultraphosphite, Fig. 2a), which can further be oxidised resulting in an ultraphosphate (12).

Initially, the reaction of three equivalents of tetrabutylammonium (TBA) phenyl phosphate with tris(diethylamino)phosphine (16) and ethylthiotetrazole (ETT) was studied: ${ }^{1} \mathrm{P}\left\{{ }^{1} \mathrm{H}\right\}-\mathrm{NMR}$ of the mixture showed consumption of $\mathbf{1 6}$ within a few minutes, giving rise to the ultraphosphite intermediate. The absence of peak splitting due to homonuclear P-P coupling for this mixed $\mathrm{P}(\mathrm{III})-\mathrm{P}(\mathrm{V})$-anhydride is in accordance with earlier observations for P-amidite couplings ${ }^{37}$. Oxidation with $m \mathrm{CPBA}$ gave phenylmodified ultraphosphate 20, which was isolated by precipitation with $\mathrm{Et}_{2} \mathrm{O}$ (71\% yield, 78\% purity, measured by $\left.{ }^{31} \mathrm{P}\left\{{ }^{1} \mathrm{H}\right\}-\mathrm{NMR}\right)$. As decomposition products, diphenyl triphosphate (10\%) and phenyl phosphate $(10 \%)$ were detected. The central ultraphosphate signal, now showing the expected multiplicity (quartet) with a chemical shift of ca. $\delta=-35 \mathrm{ppm}$, was detected in water. This finding is in sharp contrast to the antibranching-rule, claiming the instantaneous hydrolysis of ultraphosphates $3,10,24$. Purification was possible in aqueous buffer $\left(\mathrm{NH}_{4} \mathrm{HCO}_{3}\right)$ using strong anion exchange chromatography (SAX) and ${ }^{31} \mathrm{P}\left\{{ }^{1} \mathrm{H}\right\}-$ NMR analysis of fractions showed pure 20 in solution. Lyophilization resulted in significant decomposition. We also studied $\mathrm{NaClO}_{4}$ or $\mathrm{LiCl}$ solutions as eluents in SAX and attempted to isolate the product by precipitation from acetone ${ }^{32}$. Although we were unable to isolate trisphenyl $\mathrm{uP}_{4} 20$ using this procedure, trisadenosine ultraphosphate (21) precipitated and afforded the product in $55 \%$ yield. ${ }^{31} \mathrm{P}\left\{{ }^{1} \mathrm{H}\right\}-\mathrm{NMR}$ of the precipitate showed pure ultraphosphate, but after drying, decomposition $(>15 \%)$ was detected.

Next, we evaluated the scope of ultraphosphate synthesis (see Fig. 2b) by changing modifications on the terminating phosphates. Since not all products precipitated readily, reaction yields as derived for $\mathbf{2 1}$ cannot be given and Fig. $2 \mathrm{~b}$ lists the purities of crude products according to ${ }^{31} \mathrm{P}\left\{{ }^{1} \mathrm{H}\right\}$-NMR. Alkyne modified ultraphosphates (24 and $\mathbf{2 5}$ ) were readily accessible. Efforts towards the synthesis of amino-acid- and carbohydrate-modified ultraphosphates using $O$-phospho-L-tyrosine or a-D-glucose-1phosphate resulted in side-reactions of the phosphoramidite with the amine or the primary alcohol, respectively. Application of Fmoc-O-phospho-L-tyrosine followed by deprotection of the amine gave access to amino-acid modified ultraphosphate 27. The use of D-glucose-6-phosphate enabled access to a carbohydrate-containing ultraphosphate 28. Thiamine-derived ultraphosphate 29 could be obtained from the tetrakis[3,5bis(trifluoromethyl)phenyl]borate salt of thiamine phosphate. Modification of the oxidation $\left(\mathrm{S}_{8}\right.$ or $\left.\mathrm{KSeCN}\right)$ facilitated entry into thio- (in green) and seleno- (23) ultraphosphates.

Unmodified and unsymmetrical ultraphosphates. We envisioned the synthesis of inorganic ultraphosphate $\mathrm{uP}_{4}(2)$ as the defining minimal unit of this substance class. Reactions of phosphoric acid with $\mathbf{1 6}$ were unsuccessful thus requiring protected precursors for 2 . Different cleavage strategies for the protected phosphates were considered, including hydrogenolytic (30), enzymatic (31, discussed later), phototriggered (32-36) and basic (37) deprotection (see Fig. 2b). We found that ( $9 H$-fluorenyl-9-yl)methyl (Fm) dihydrogen phosphate was readily accessible $^{38}$ and that the corresponding ultraphosphate $\mathbf{3 7}$ could be synthesised under ambient conditions. 37 could also be stored indefinitely in solution at $-20^{\circ} \mathrm{C}$ after purification, enabling screening of several bases for deprotection. Only DBU enabled deprotection to 37 , but precipitation of $\mathrm{uP}_{4} 2$ resulted in decomposition.

Unsymmetrically modified ultraphosphates were accessible by orthogonal activation strategies using chlorophosphoramidites (39 or 41, see Fig. 3a). Although over-reaction in the first and unselective phosphate exchange in the second step was observed, a series of unsymmetrical ultraphosphates were obtained after purification. Fm-modified structures further allowed deprotection by the addition of DBU to yield twofold or singly modified ultraphosphates (50-54, see Fig. 3c). The number of 


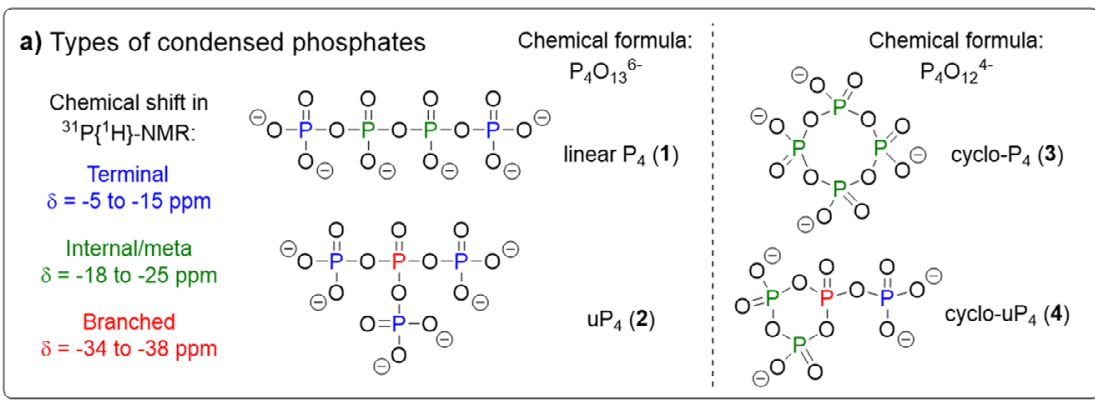

b) Polydisperse ultraphosphates

Synthesis from metal oxides or carbonates and $85 \%$ phosphoric acid or $\mathrm{P}_{2} \mathrm{O}_{5}$, high temp.

$$
\left(0<\mathrm{M}_{2} \mathrm{O} / \mathrm{P}_{2} \mathrm{O}_{5}<1\right)
$$

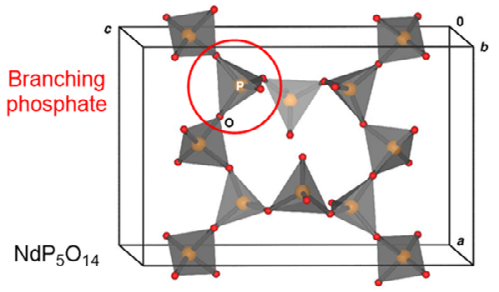

c) Monodisperse ultraphosphates

$$
\begin{aligned}
& \text { Glonek }
\end{aligned}
$$

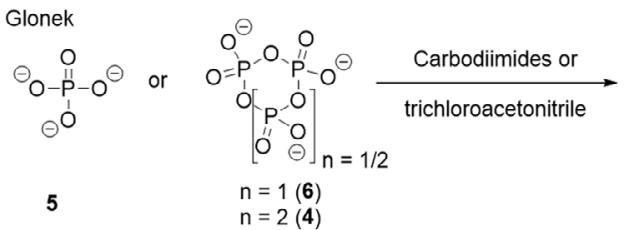

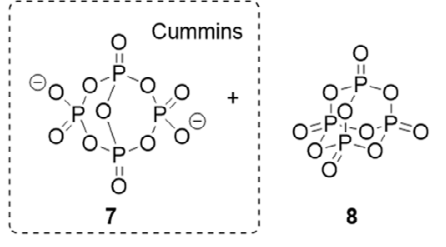

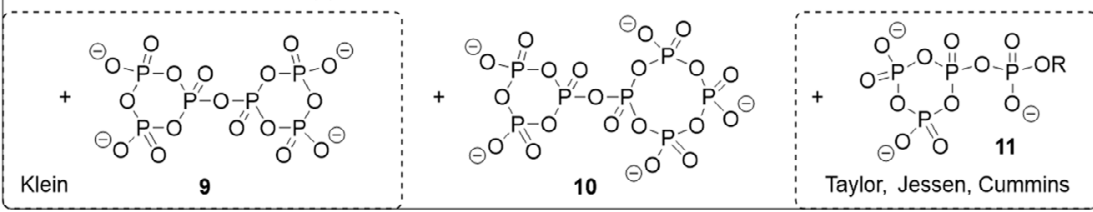

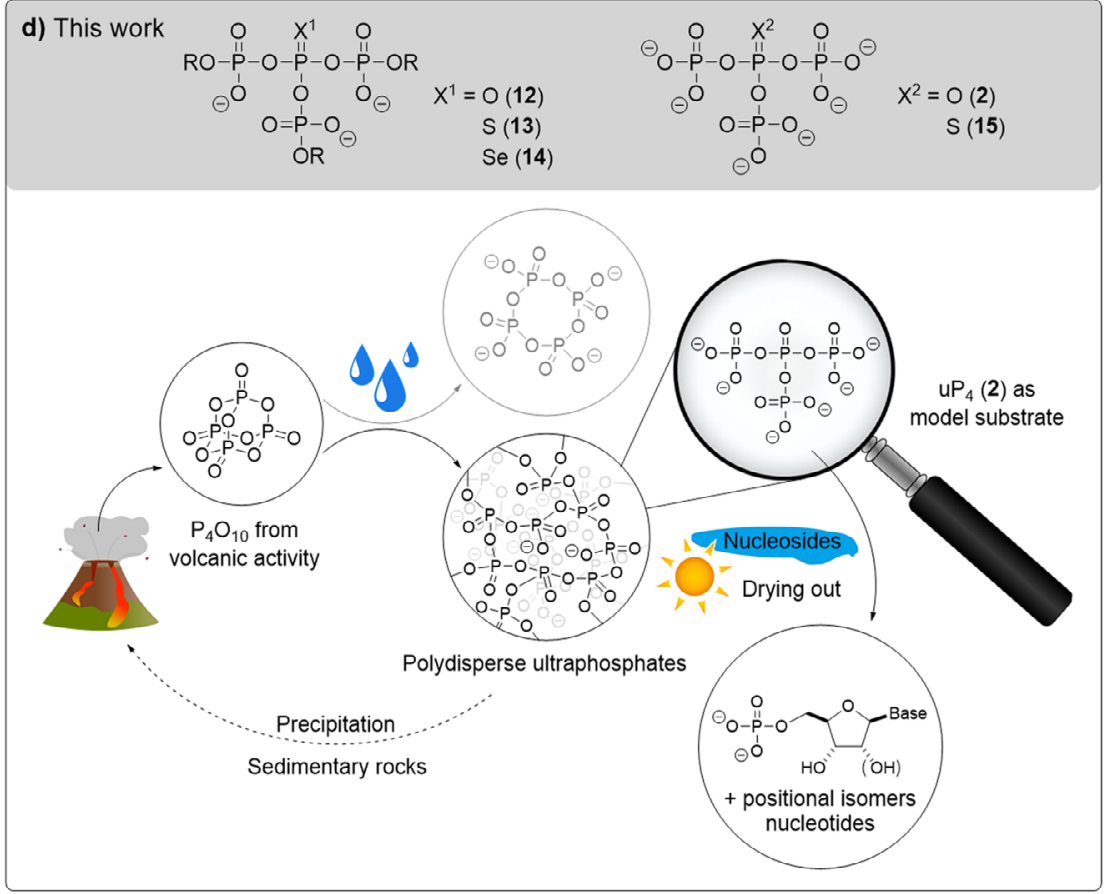

Fig. 1 Previous work on cyclic ultraphosphates and non-cyclic ultraphosphates in this work with implications for prebiotic chemistry. a Types of condensed phosphates and their chemical shift in ${ }^{31} \mathrm{P}\left\{{ }^{1} \mathrm{H}\right\}-N M R$. b General synthesis protocol for polydisperse ultraphosphates and crystal structure of $\mathrm{NdP}_{5} \mathrm{O}_{14}{ }^{61}$. c Monodisperse ultraphosphates detected by Glonek in the condensation reactions of orthophosphoric acid or metaphosphates using carbodiimides or trichloroacetonitrile ${ }^{24-28}$. The structures in dashed boxes were further described in publications by Klein ${ }^{62}$, Taylor $^{29}$, Jessen $^{31,} 32$ and Cummins $^{33}$. d General structures of ultraphosphates in this work and suggestion for prebiotically plausible phosphorylation reactions using ultraphosphates: $\mathrm{uP}_{4}(\mathbf{2})$ was used as a model substrate for polydisperse ultraphosphates arising from reactions of $\mathrm{P}_{4} \mathrm{O}_{10}$ in the presence of water ${ }^{59}$. The prebiotic phosphate cycle including phosphorus pentoxide from volcanic activity has already been proposed and meets the challenge of making phosphate available from low-solubility minerals ${ }^{56-58,63}$ 


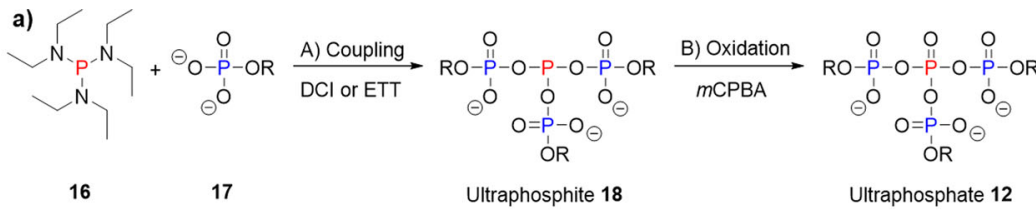

(i) ${ }^{31} \mathrm{P}\left\{{ }^{1} \mathrm{H}\right\}-$ NMR of trisadenosine ultraphosphite (19)
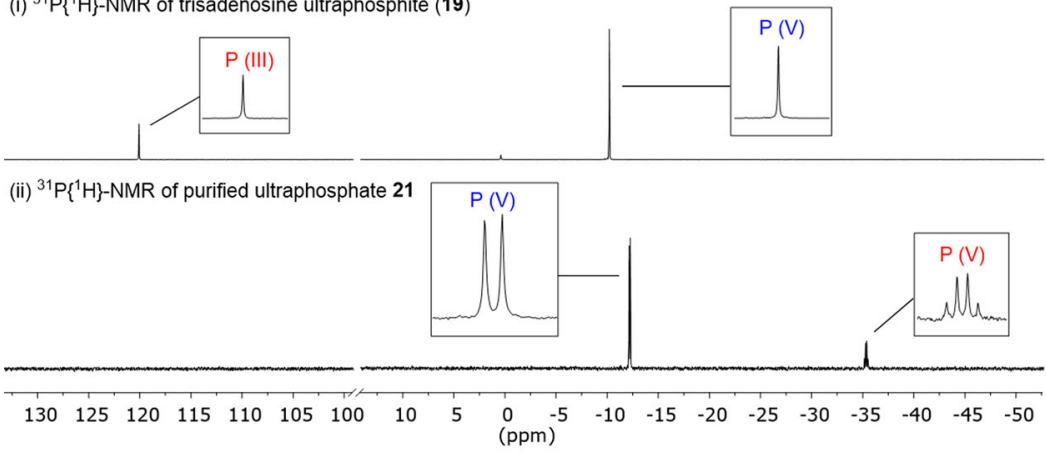

b)

$\mathrm{R}=$

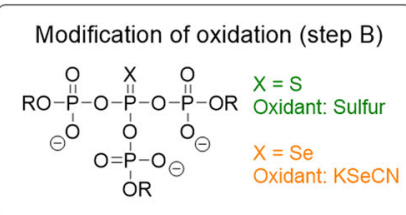

3

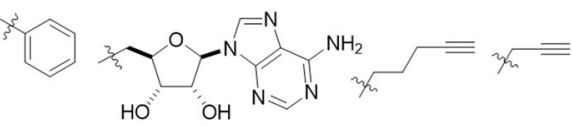

$\begin{array}{llllll}\text { Purity of crude } & \mathbf{2 1} & \mathbf{2 2} & 23 & 24 & \mathbf{2 5}\end{array}$<smiles>[Y6][Y10]#CCc1sc[n+](Cc2cnc(C)nc2N)c1C</smiles>

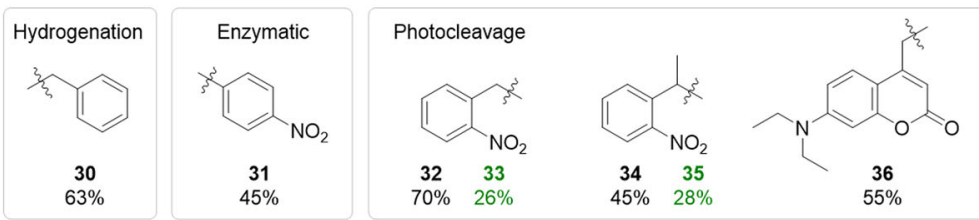

X-ray strcuture of 37 :
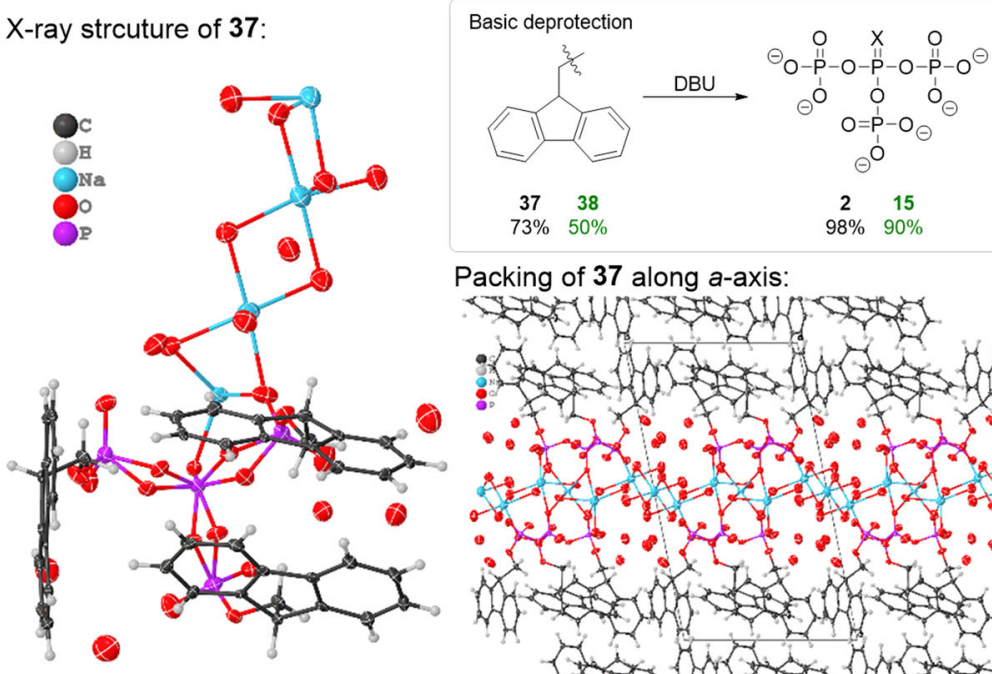

Packing of $\mathbf{3 7}$ along a-axis:
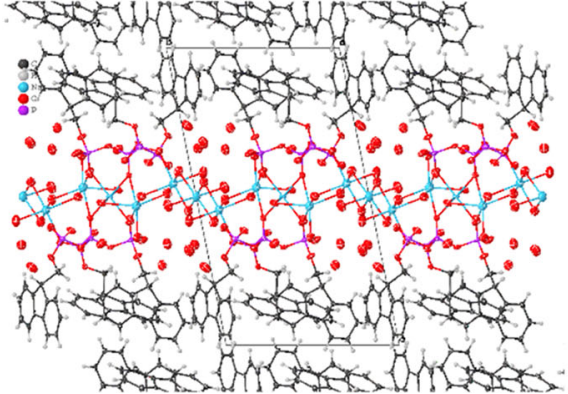

Fig. 2 Symmetrical ultraphosphates. a Synthesis of ultraphosphates by threefold coupling of phosphates with tris(diethylamino)phosphine $\mathbf{1 6}$ and subsequent oxidation. ${ }^{31} \mathrm{P}\left\{{ }^{1} \mathrm{H}\right\}-N M R$ spectra of the intermediary ultraphosphite $\mathbf{1 9}$ and the ultraphosphate $\mathbf{2 1}$ after oxidation and purification for $R=$ adenosine. $\mathbf{b}$ Synthetic scope of the synthesis of symmetrically modified ultraphosphates and modification of the oxidation step to yield thio- and seleno analogues. The purity of the crude products is given in percent according to the ${ }^{31} \mathrm{P}\left\{{ }^{1} \mathrm{H}\right\}$-NMR spectra. Yields were not determined due to uncertain quantities of counterions but the respective crude masses are reported in the supporting information along with the spectra. 
a) Threefold modified unsymmetrical ultraphosphates

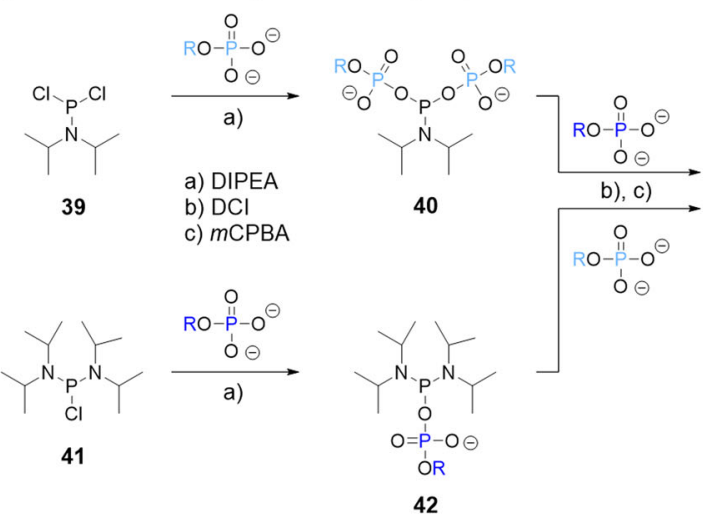

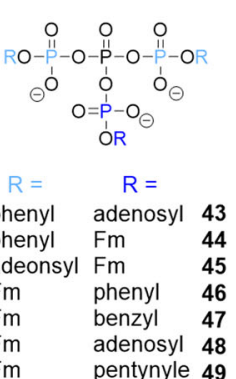

pentynyle 49

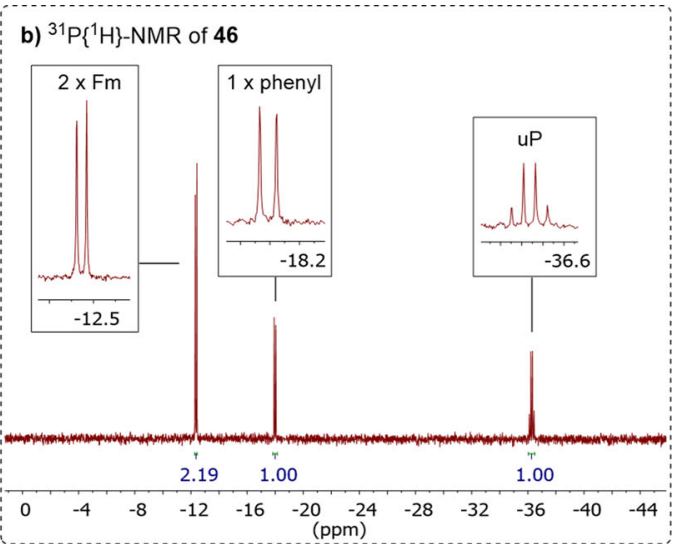

c) Twofold and singly modified ultraphosphates

d) Click-chemistry on $\mathbf{4 9}$

Fm-modified structures 44 to 48 were deprotected by addition of DBU

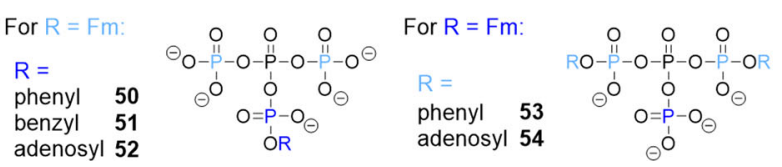

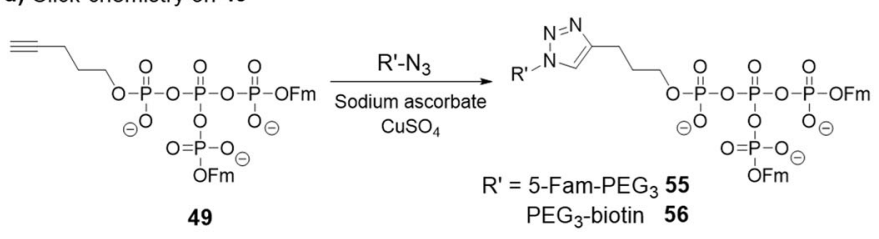

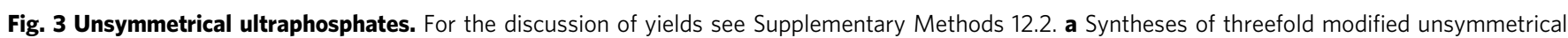
ultraphosphates using either a chloro phosphormono- or diamidite. b ${ }^{31} \mathrm{P}\left\{{ }^{1} \mathrm{H}\right\}-\mathrm{NMR}$ spectrum of unsymmetrically modified ultraphosphate 46. c Twofold and singly modified ultraphosphates by deprotection of Fm-modified, unsymmetrical ultraphosphates using DBU. d Application of click-chemistry on ultraphosphate $\mathbf{4 9}$.

modifications influenced the stability of the ultraphosphate towards hydrolysis, showing faster decomposition for twofold modified structures. For example, $\mathbf{5 4}$ was completely hydrolysed in the deprotection mixture (5\% DBU in water, $\mathrm{pH} 13.9$ ) within $30 \mathrm{~min}$ while $\mathbf{5 2}$ had a half-life of $180 \mathrm{~min}$. Copper-catalysed click reactions on 49 were performed with biotin and fluoresceinconjugates and allowed the preservation of the ultraphosphate (Fig. 3d).

Salt metatheses and crystallisation. To obtain a single crystal of an ultraphosphate, we examined salt metatheses reactions to yield $[\mathrm{PPN}]$ salts, as [PPN] is well-known for its high crystallinity and its capability to stabilise anions ${ }^{39}$. We developed a method to isolate the ultraphosphate [PPN] salts from fractions after SAX purification (Supplementary Fig. 2) and found that they can be dried and stored indefinitely, in contrast to non-[PPN] salts. Only $\mathrm{uP}_{4}[\mathrm{PPN}]$ decomposed as soon as residual water was removed.

Although no crystals of sufficient quality for crystal structure analysis could be obtained from the [PPN] salts, it was found that Fm-protected 37 can be salted out from solutions after reversedphase purification (55\% water, $35 \% \mathrm{MeCN}, 10 \%$ TEAA $(100 \mathrm{mM}$, $\mathrm{pH} 7.0)$ ) by addition of $\mathrm{NaCl}$ and that these conditions supported the formation of single-crystals. X-ray diffraction studies established the identity of 37 (Fig. 2). The packing along the a-axis (Supplementary Fig. 3) shows that the ultraphosphate is arranged along a chain of water-bridged sodium cations to form distinct layers where hydro- and lipophilic interactions are maximised. We attribute the increased stability of $\mathbf{3 7}$ compared to other symmetrically modified ultraphosphates to a steric shielding of the ultraphosphate moiety. Accordingly, the comparably lower stability of singly or twofold modified ultraphosphates can be explained. However, as a counter-effect, the higher negative charge enables longer half-lives of singly compared with twofold modified structures. Although [PPN] salts are stable storage forms for ultraphosphates, their insolubility in water can be disadvantageous. The metathesis to water-soluble sodium salts was possible using $\mathrm{NaOTf}$. Only for $\mathrm{uP}_{4}$, the salt metathesis was unsuccessful and led to the formation of inorganic mono- and triphosphate. Unexpectedly, also pyro- (14\%) and linear tetraphosphate $(12 \%)$ were detected.

Stability of ultraphosphates in water. The antibranching-rule describes ultraphosphates as exceedingly unstable in the presence of water ${ }^{12,13}$. Our observations, however, revealed significant hydrolytic stability for short-chain ultraphosphates expressed in half-lives ranging from several hours to days. The decomposition of $\mathrm{uP}_{4}$ and trisadenosine $\mathrm{uP}_{4} 21$ was tracked by ${ }^{31} \mathrm{P}\left\{{ }^{1} \mathrm{H}\right\}-\mathrm{NMR}$ at different $\mathrm{pH}$ values and in the presence of different cations (see Fig. 4a and Supplementary Fig. 4). There is a high $\mathrm{pH}-$ dependency on the decomposition rates, with longer half-lives obtained with increasing $\mathrm{pH}$ values. In the presence of $\mathrm{Mg}^{2+}$, the decay was about twice as fast, and $\mathrm{Ca}^{2+}$ accelerated the decay even further. In contrast, monovalent cations had only little effect.

The stability of ultraphosphates suffices to subject them to polyacrylamide gel electrophoresis on dense gels (PAGE; Supplementary Fig. 5 and Supplementary Fig. 6) without significant decomposition followed by staining with toluidine blue $^{40}$. Such separations take several hours in aqueous buffer. Threefold modified ultraphosphates gave clear bands without any observed decay and even $\mathrm{uP}_{4}$ could be analysed by PAGE, pointing towards a possible analytical approach to detect ultraphosphates in biological samples. Singly or twofold modified structures 52 and $\mathbf{5 4}$ decomposed under these conditions.

Enzymatic digestion of ultraphosphates. Ultraphosphates have not been reported to occur in biological systems ${ }^{41}$. Since polyP extraction protocols usually include acidic conditions, nucleophilic reagents, divalent cations and drying-all of which accelerate ultraphosphate decomposition-one would not expect to detect ultraphosphates. The publication by Hong provides evidence for this case already for the more stable metaphosphates ${ }^{9}$. 
a)

$$
\begin{aligned}
& \begin{aligned}
0 \\
0
\end{aligned} \\
& \text { RO- } \mathrm{P}-\mathrm{O}-\mathrm{P}-\mathrm{O}-\mathrm{P}-\mathrm{OR} \quad \mathrm{Hydrolysis} \quad \Theta^{\mathrm{O}} \Theta^{\mathrm{O}} \Theta^{\mathrm{O}}
\end{aligned}
$$

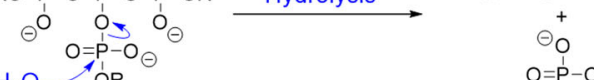

\begin{tabular}{|c|c|c|c|c|c|}
\hline \multicolumn{6}{|c|}{ Hydrolysis half-lives } \\
\hline \multicolumn{2}{|c|}{ Addition of $0.1 \mathrm{eq}$. salt } & $\mathrm{pH} 4.7$ & $\mathrm{pH} 6.0$ & $\mathrm{pH} 10.0$ & $\mathrm{pH} 13.9$ \\
\hline \multirow{2}{*}{$\mathrm{R}=\ominus\left(\mathrm{uP}_{4}\right)$} & No salt & & & $12.5 \mathrm{~h}$ & $47.4 \mathrm{~h}$ \\
\hline & $\mathrm{MgCl}_{2}$ & & & $5.6 \mathrm{~h}$ & $22.4 \mathrm{~h}$ \\
\hline \multirow{4}{*}{$\begin{array}{l}\mathrm{R}=\underset{(21)}{\operatorname{adenosine}} \\
\text { (21) }\end{array}$} & No salt & $4.2 \mathrm{~h}$ & $7.1 \mathrm{~h}$ & $16.0 \mathrm{~h}$ & \\
\hline & $\mathrm{NH}_{4} \mathrm{Cl}$ & $4.1 \mathrm{~h}$ & $6.5 \mathrm{~h}$ & $15.4 \mathrm{~h}$ & \\
\hline & $\mathrm{MgCl}_{2}$ & $3.3 \mathrm{~h}$ & $4.8 \mathrm{~h}$ & $7.5 \mathrm{~h}$ & \\
\hline & $\mathrm{CaCl}_{2}$ & $2.0 \mathrm{~h}$ & $2.5 \mathrm{~h}$ & $3.1 \mathrm{~h}$ & \\
\hline
\end{tabular}

$$
\begin{aligned}
& \mathrm{H}_{2} \mathrm{O}
\end{aligned}
$$

b)

b) $\quad \mathrm{O}_{2} \mathrm{~N}$

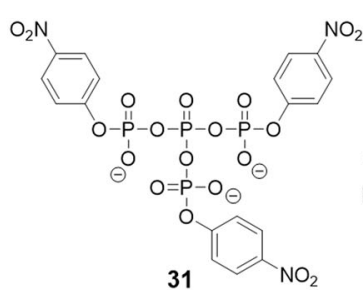

$\mathrm{NO}_{2}$

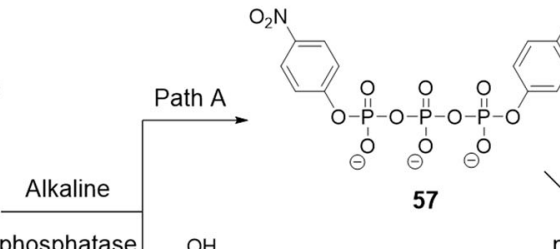

$\mathrm{NO}_{2}$

(ALP)
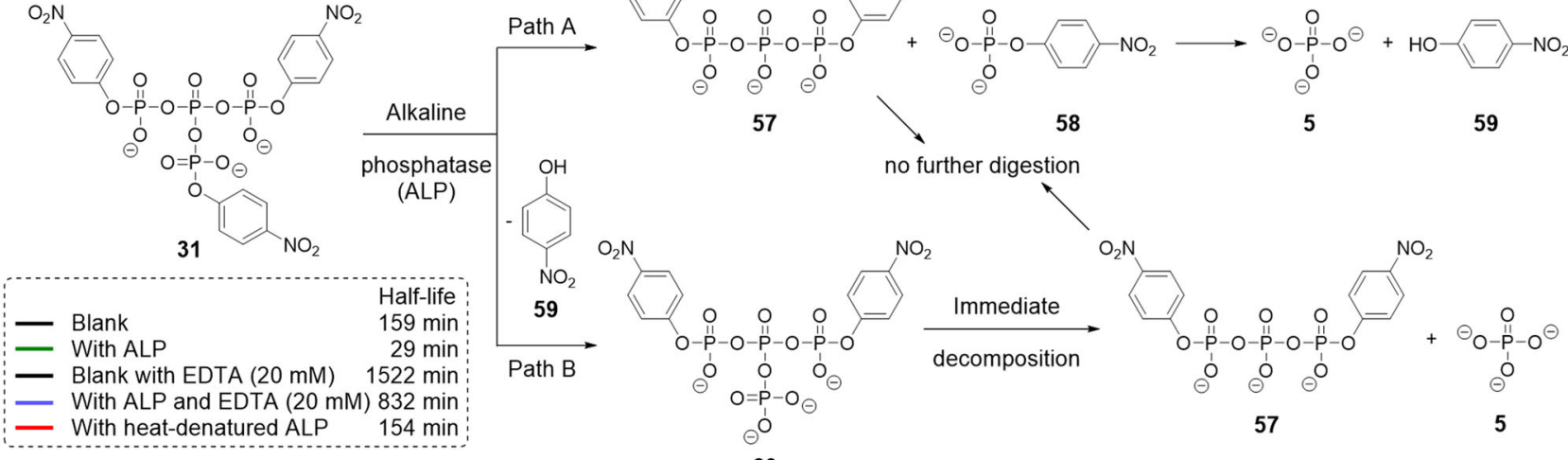

no further digestion
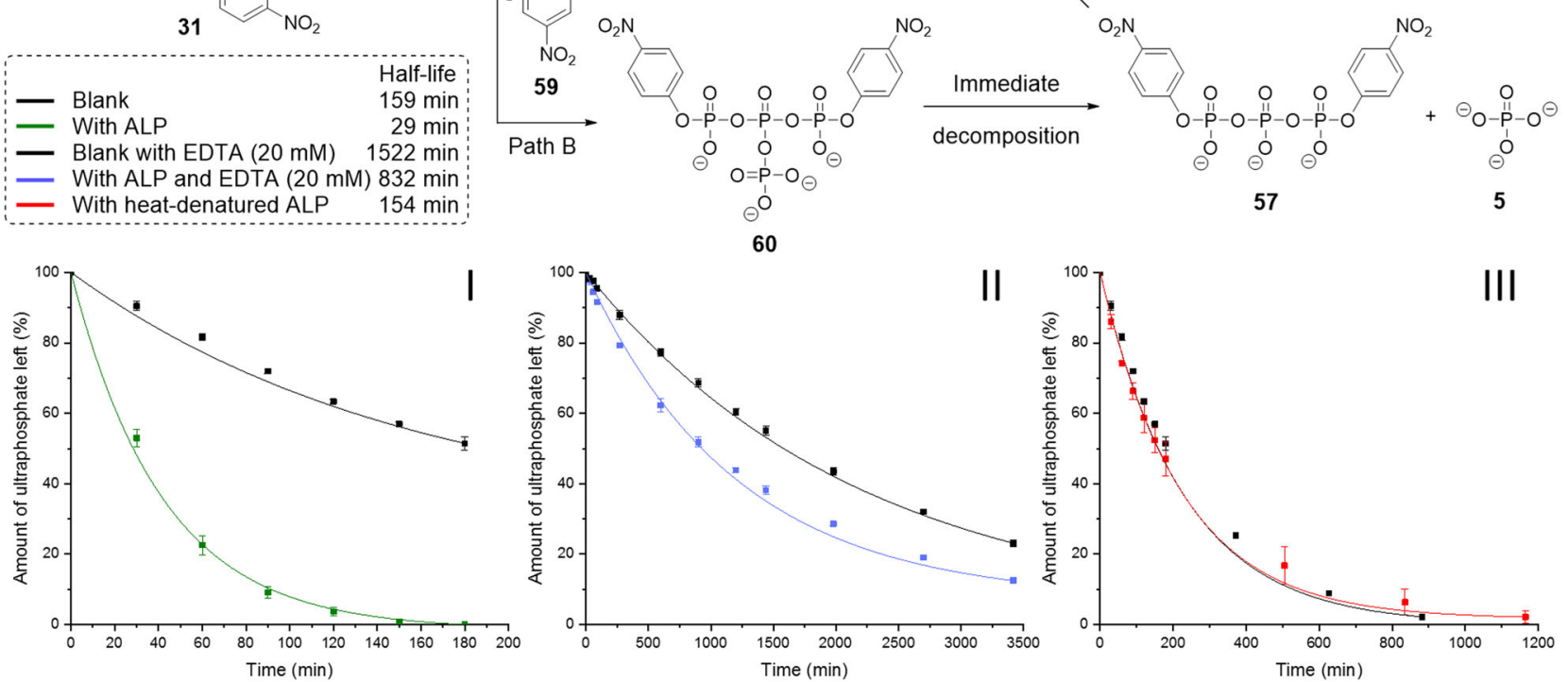

c) $\mathrm{O}_{2} \mathrm{~N}$

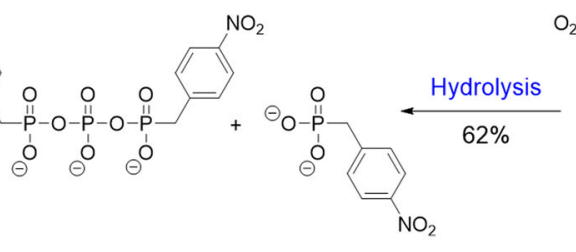

61

62

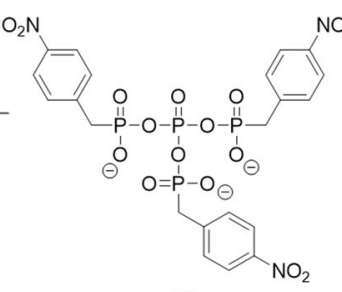

63
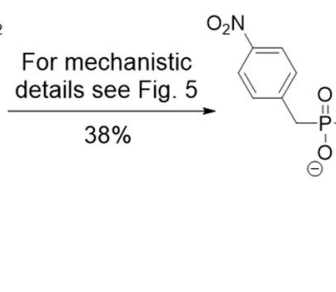

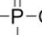

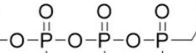

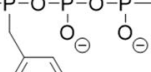

$\mathrm{NO}_{2}$

64

Fig. 4 Stability of ultraphosphates in aqueous media and enzymatic digestion. a Decomposition of trisadenosine ultraphosphate $(\mathbf{2 1})$ and $\mathrm{uP}_{4}$ under different $\mathrm{pH}$ values and in presence of 0.1 eq. of different cations. Half-lives were calculated assuming pseudo-first-order reaction kinetics. $\mathbf{b}$ Enzymatic digestion of tris (para-nitrophenyl) ultraphosphate (31) by alkaline phosphatase (ALP) from bovine intestinal mucosa. Kinetics were recorded using ${ }^{31} \mathrm{P}\left\{{ }^{1} \mathrm{H}\right\}-N M R$ and the $[\mathrm{PPN}]$ signal was used as an internal standard. The results are means \pm standard deviation from experiments performed in triplicates. Half-lives were calculated assuming pseudo-first-order reaction kinetics. I, 31 in the presence (green) and absence (black) of ALP. II, 31 with 20 mm EDTA in the presence (blue) and absence (black) of ALP. III, $\mathbf{3 1}$ in the presence (red) and absence (black) of heat-inactivated ALP. c Decomposition of tris(paranitrobenzyl phosphonyl) ultraphosphate (63).

In accordance, we could not find any ultraphosphate signal at ca. $\delta=-35 \mathrm{ppm}$ in ${ }^{31} \mathrm{P}\left\{{ }^{1} \mathrm{H}\right\}-\mathrm{NMR}$ analyses of polyP extracts from different yeast strains modified in their polyP metabolising enzymes (the polyP overexpressor GPD-vtc5, the polyP devoid $\Delta$ vtc4, and polyP accumulating $\Delta$ ppn1, ppn2, ppx1, that lack phosphatases degrading polyP; Supplementary Fig. 7 and 8). We hypothesised that in addition to chemical conditions, enzymes might also degrade ultraphosphates, which would further complicate strategies to extract them from biological sources. We studied the enzymatic digest of ultraphosphates using alkaline phosphatase (ALP). We initially examined the hydrolysis of paranitrophenylphosphate and its ultraphosphate 31. We synthesised ultraphosphate 31 as its [PPN] salt and tracked the decomposition in the presence and absence of ALP by ${ }^{31} \mathrm{P}\left\{{ }^{1} \mathrm{H}\right\}-\mathrm{NMR}$ (Fig. 4b) ${ }^{42} .31$ showed a half-life of $t_{1 / 2}=159 \mathrm{~min}$ in the absence of the enzyme, which was significantly reduced upon its addition 
$\left(t_{1 / 2}=29 \mathrm{~min}\right)$. We were interested as to whether the ultraphosphate 31 binds to the active site or whether surface effects are responsible for the accelerated hydrolysis. We measured additional kinetics using either heat-denatured enzyme or enzymetreated with ethylenediaminetetraacetic acid (EDTA) to remove $\mathrm{Mg}^{2+}$ and $\mathrm{Zn}^{2+}$ ions. The decay of 31 in presence of heatinactivated enzyme copies the kinetics of the blank. Only a low residual hydrolytic activity in the presence of EDTA was found. We conclude that ultraphosphate $\mathbf{3 1}$ binds to the active site and is enzymatically digested, providing evidence for an ultraphosphate-enzyme interaction. Similar results were obtained for the adenosine-modified ultraphosphate 21 (Supplementary Fig. 9). However, it was still unclear whether ALP first hydrolyses the branching point of ultraphosphates, or one of the three phosphoester bonds (path A or B in Fig. 4b). The latter would result in an unstable twofold modified ultraphosphate $\mathbf{6 0}$ that would rapidly decay further. $\mathrm{uP}_{4} \mathbf{2}$ was enzymatically digested as well (Supplementary Fig. 10), pointing towards the cleavage of the anhydride bond. To further study the enzymatic digestion of modified ultraphosphates, we envisioned the synthesis of the nonhydrolyzable analogue 63 with a $\mathrm{CH}_{2}$-group as an oxygen replacement, which the enzyme cannot cleave, whereas still being capable of hydrolysing the central anhydrides (Fig. 4c). paraNitrobenzyl phosphonic acid was transformed to ultraphosphonate 63. After oxidation, ${ }^{31} \mathrm{P}\left\{{ }^{1} \mathrm{H}\right\}-\mathrm{NMR}$ suggested a clean reaction to the product, but after precipitation, ultraphosphonate 63 was no longer present (Supplementary Fig. 11). We identified the usual hydrolysis products $\mathbf{6 1}$ and $\mathbf{6 2}$ but also another product, which was purified by AIEX chromatography and found to be a linearised mixed tetraphosphonate/phosphate analogue 64. This is reminiscent of the linear tetraphosphate we found for $\mathrm{uP}_{4} 2$ decomposition described earlier and pointed towards a rearrangement typical for ultraphosphates.

Ultraphosphates rearrange by phosphate walk. Apart from linearised products such as $\mathrm{P}_{4}$ from $\mathrm{uP}_{4}[\mathrm{PPN}] 2$ and the synthesis of an ultraphosphonate (63 and 64, Fig. 4c and Supplementary Fig. 11), trisadenosine ultraphosphate [PPN] (21) also showed another decay mechanism accompanying simple hydrolysis of the branching point after several days in DMF. Next to $\mathrm{AMP}$ and $\mathrm{Ap}_{3} \mathrm{~A}$ as expected products of hydrolysis, further signals were detected and ${ }^{1} \mathrm{H}-{ }^{31} \mathrm{P}-\mathrm{HMBC}$ cross-peak analysis revealed that internal phosphates must carry adenosine (Fig. 5a). The mixture was analysed by CE-MS, which enabled the separation of different components and determination of their mass. We confirmed masses matching $\mathrm{Ap}_{2} \mathrm{~A}$, a threefold modified triphosphate $\mathbf{6 5}$ as well as a threefold modified tetraphosphate $\mathbf{6 6}$. Since 21 was analytically pure, a rearrangement must lead to linearization of the ultraphosphate that walks into the line $e^{43}$, which we dub the phosphate walk (Fig. 5b). We propose, that the ultraphosphate linearises by an attack of one terminal phosphate at another accompanied with the cleavage of either a phosphoanhydride or phosphoester bond. The latter would form a cyclic ultraphosphate intermediate and requires a second nucleophilic attack of the released alcoholate to form $\mathbf{6 6}$ as the central intermediate of the mechanism. Depending on the nucleophile (AMP or $\mathrm{H}_{2} \mathrm{O}$ ) and the attacked phosphate of $\mathbf{6 6}$ (Fig. 5b), both the internally modified phosphate 65 and $\mathrm{Ap}_{2} \mathrm{~A}$, as well as standard decomposition products, can be explained.

Bisphenyladenosine (43) and trisbenzyl ultraphosphate (30) [PPN] (Supplementary Fig. 12 and Supplementary Fig. 13) also showed phosphate walk products. For 30, the rearrangement could only be induced by heating to $80^{\circ} \mathrm{C}$.
Computation was invoked to corroborate the feasibility of the internal phosphate walk mechanism. The electronic states and chemical bonding of branched phosphates in phosphate glasses have been discussed based on computational results for various model clusters ${ }^{44}$. However, the history of mechanistic disputes surrounding substitution reactions at phosphorous includes a myriad of experimental results and ab initio computations ${ }^{45-47}$. The energy of highly charged species, with variable counterions in high vs moderate dielectrics involving hydrogen bond donors, are sensitive to intricate changes in speciation, constitutional and conformation isomerism, and explicit vs continuum environmental effects ${ }^{4-49}$. Mechanistic computational studies involving trimethyl ultraphosphate (67) at the B97D/Def2-TZVPD(water) level of theory support the ultraphosphate $\mathbf{6 7}$ and linearised product 69 having energies compatible with both species being accessible under normal conditions. A cyclic intermediate $\mathbf{6 8}$ (Fig. 5c) was found that results formally from the loss of methoxide and the formation of a six-membered ring by the association of formally negative oxygen of one phosphate to the phosphorous where methoxide is removed. These three states (67-69) were the basic minima considered. The walk could occur through this higher energy cyclic state that serves as a possible bridge between branched and linear forms and has transition states leading to the ring-formation and -opening. Alternatively, the association could form a ring with a pentavalent phosphorous atom (70); however, numerous attempts to identify such an intermediate by DFT calculations were unsuccessful. Mono- and dihydrates were considered, where the explicit waters were placed in positions consistent with prevailing models ${ }^{47}$ bringing down the relative activation energies. The data support a trend where reaction in water coupled to specific acid catalysis would show fast substitution rates. Considering effective molarities, relative nucleophilicities and the high concentration of water in water $(55 \mathrm{M})$, hydrolysis as the dominant reaction path is not surprising. Taken out of the context of water, the effective molarity of internal nucleophile remains constant; the nucleophilic strength of solvent is reduced and the concentration of solvent molecules as nucleophiles in bulk solvent drops to on the order of $10 \mathrm{M}^{50,51}$. All these factors presage parallel rates of acceleration in the presence of acid but a product distribution in which internal attack becomes competitive if not fully dominant. This shift in product distribution opens the way for the phosphate walk. For the ultraphosphonate analogue 63, however, the one-step mechanism must be energetically favoured.

Reactivity of $\mathbf{u P}_{4}$ as phosphorylating agent. Ultraphosphates could potentially serve as phosphorylating reagents if suitable nucleophiles are present, as has been previously studied for polyand metaphosphates ${ }^{52-55}$. Earlier studies suggested the formation of branched phosphates on primitive earth as partial hydrolysis products of $\mathrm{P}_{4} \mathrm{O}_{10}$, which in turn can be volatilised from magma ${ }^{7,56-58} \cdot \mathrm{uP}_{4} 2$ was used as a model substrate for polydisperse ultraphosphates arising from $\mathrm{P}_{4} \mathrm{O}_{10}$ in the presence of water ${ }^{59}$ to study the potential contribution of branched phosphates to prebiotic phosphorylation reactions (Fig. 6a and Supplementary Fig. 15). Aliphatic nucleophiles were studied for general reactivity patterns of ultraphosphates. Ethanolamine was used to screen the required stoichiometry to favour the phosphorylation reaction over simple hydrolysis by water. We observed monophosphorylation of the amine moiety with a phosphorylation ratio of up to $85: 15$ (phosphorylated ethanolamine vs. orthophosphate as hydrolysis product) with 3000 eq. ethanolamine. Decreasing ethanolamine gave ratios of 70:30 for 500 eq. and 27:73 phosphorylated ethanolamine for 100 eq., respectively. For secondary amines and alcohols, 
a)

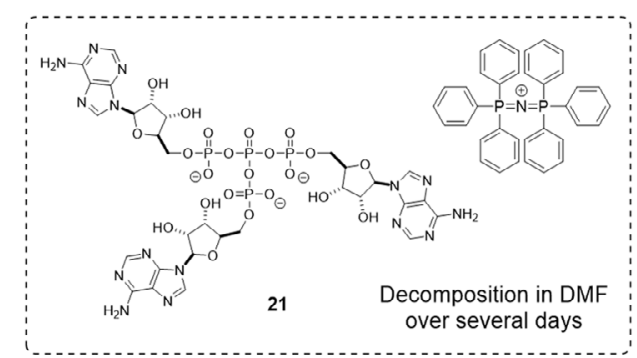

rysume
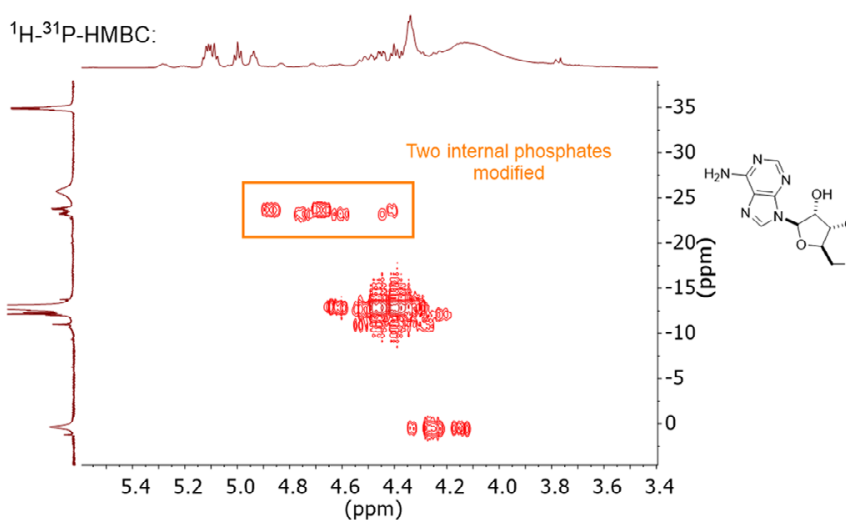

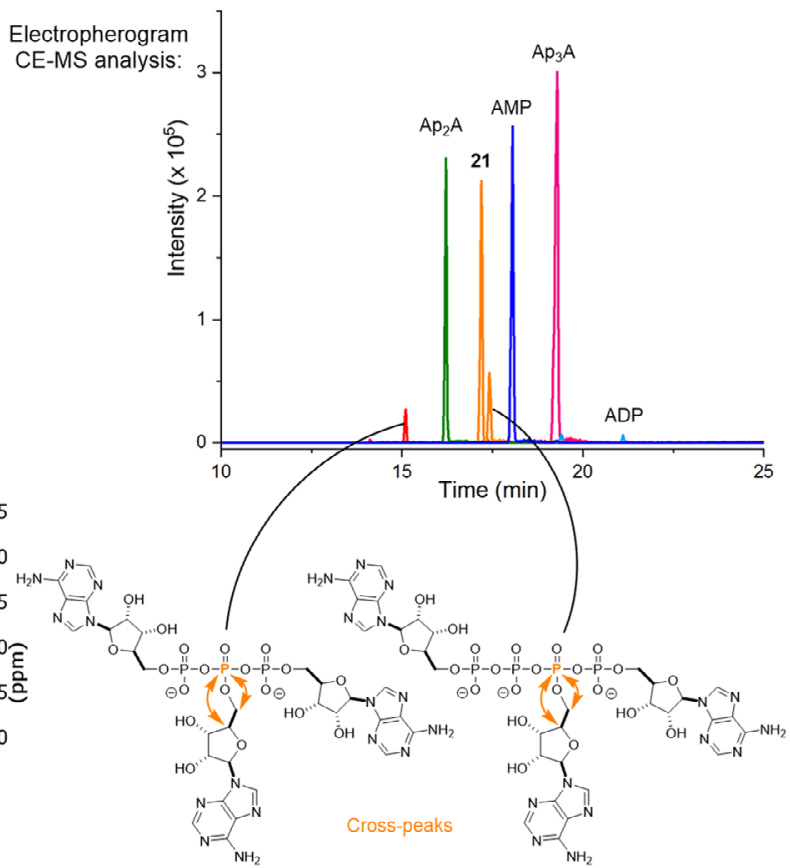

65

66
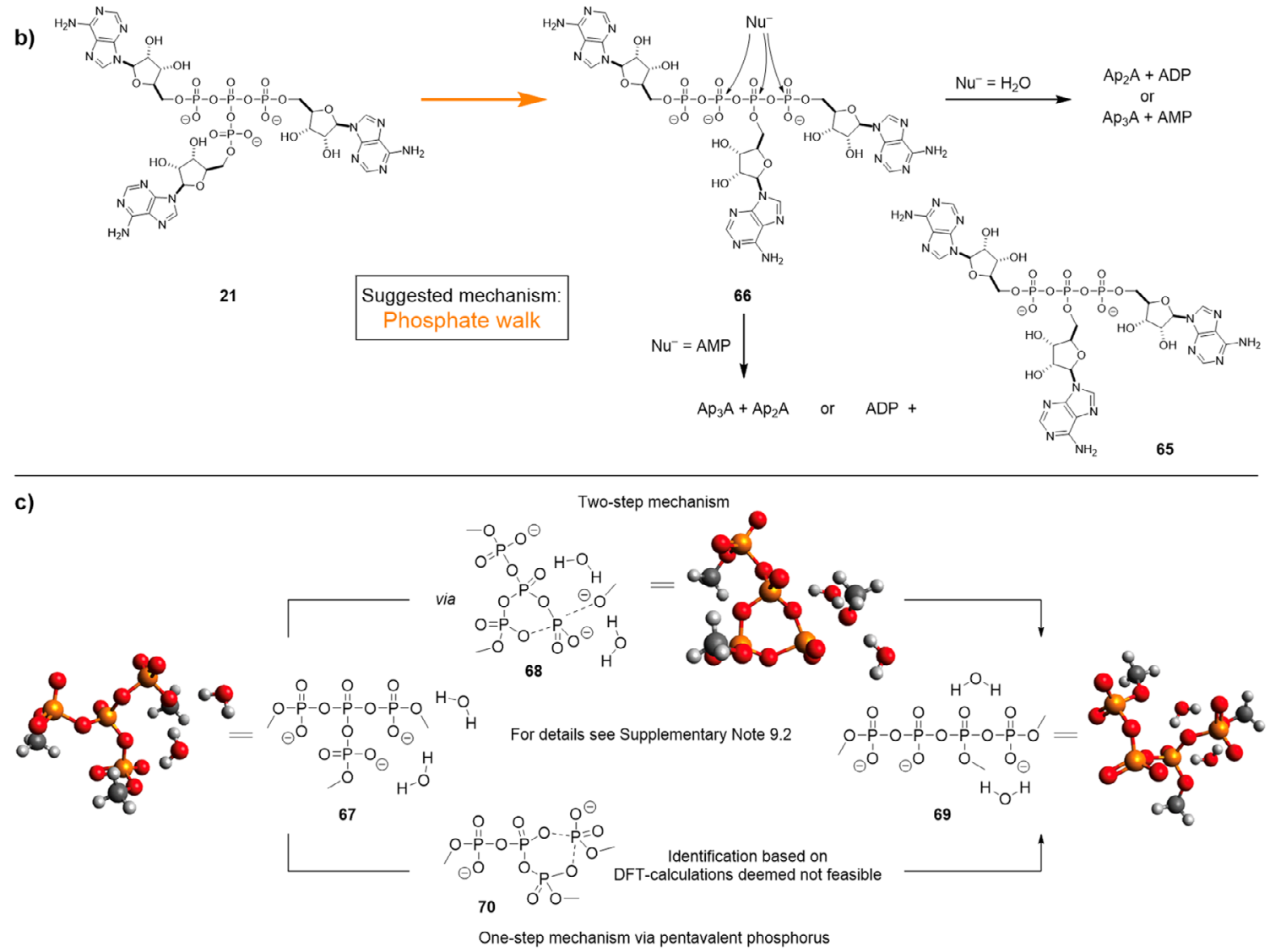

Fig. 5 Rearrangement of ultraphosphates. a Analytical results for trisadenosine ultraphosphate (21) [PPN] salt after 14 days in DMF: ${ }^{1} \mathrm{H}-31 \mathrm{P}-\mathrm{HMBC}$ with two cross-peaks for internally modified oligophosphates. CE-MS analysis of the product mixture and proposed structures $\mathbf{6 5}$ and $\mathbf{6 6}$ for the internally modified compounds. b Phosphate walk rearrangement for trisadenosine ultraphosphate (21) and nucleophilic attack of the linearised product $\mathbf{6 6}$. c Possible mechanistic pathways of the phosphate walk rearrangement for trimethyl ultraphosphate dihydrate (67). Mechanistic studies were carried out at the B97D/Def2-TZVPD(water) level of theory; for details see Supplementary Note 9.2. 


\begin{tabular}{|c|c|c|c|c|c|c|}
\hline 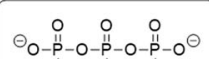 & a) & Conditions & $\begin{array}{l}\text { sphorylation/ } \\
\text { ophosphate }\end{array}$ & & Conditions & $\begin{array}{l}\text { Phosphorylation } \\
\text { orthophosphate }\end{array}$ \\
\hline 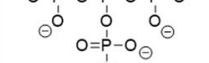 & Uridine & $\begin{array}{l}3000 \text { eq., pH } 13 \text { (DBU) } \\
3000 \text { eq., pH } 13 \text { (DBU), } 10 \text { eq. } \mathrm{MgCl}_{2}\end{array}$ & $\begin{array}{c}4: 96 \\
11: 89\end{array}$ & Thymidine & $\begin{array}{l}500 \text { eq., freeze-drying } \\
500 \text { eq., evaporation }\end{array}$ & $\begin{array}{l}41: 59 \\
19: 81\end{array}$ \\
\hline$\Theta^{0}$ & & 3000 eq., pH $13(\mathrm{NaOH})$ & $7: 93$ & & & \\
\hline & & $\begin{array}{l}3000 \text { eq., } \mathrm{pH} 13(\mathrm{NaOH}) \text {, freeze-drying } \\
3000 \text { eq., freeze-drying }\end{array}$ & & Deoxyadenosine & 500 eq., evaporation & $\begin{array}{l}23: 77 \\
14: 86\end{array}$ \\
\hline 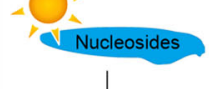 & & $\begin{array}{l}3000 \text { eq., } 80^{\circ} \mathrm{C} \\
10 \text { eq. } \mathrm{MgCl}_{2} \text {, freeze-drying } \\
100 \text { eq., freeze-drying }\end{array}$ & $\begin{array}{l}7: 93 \\
11: 89 \\
\text { (incomplete) }\end{array}$ & Guanosine & $\begin{array}{l}500 \text { eq., freeze-drying } \\
500 \text { eq., evaporation }\end{array}$ & $\begin{array}{l}40: 60 \\
23: 77\end{array}$ \\
\hline \begin{tabular}{l|l} 
Conditions & Drying out
\end{tabular} & & $\begin{array}{l}500 \text { eq., freeze-drying } \\
500 \text { eq., evaporation }\end{array}$ & $\begin{array}{l}44: 56 \\
25: 75\end{array}$ & Deoxyguanosine & $\begin{array}{l}500 \text { eq., freeze-drying } \\
500 \text { eq., evaporation }\end{array}$ & $\begin{array}{l}41: 59 \\
23: 77\end{array}$ \\
\hline$Y^{\text {Base }}$ & $\begin{array}{r}\text { Control } \\
\text { and }\end{array}$ & $\begin{array}{l}\text { experiment with each } 3000 \text { eq. of inorga } \\
\text { d triphoshpate and freeze-drying gave no }\end{array}$ & $\begin{array}{l}\text { nic mono- } \\
\text { UMP }\end{array}$ & Cytidine & $\begin{array}{l}500 \text { eq., freeze-drying } \\
500 \text { eq., evaporation }\end{array}$ & $\begin{array}{l}34: 66 \\
29: 71\end{array}$ \\
\hline $\begin{array}{l}\odot \mathrm{O} \\
+ \text { positional isomers } \\
\text { nucleotides }\end{array}$ & Adenosine & $\begin{array}{l}\mathrm{pH} 13(\mathrm{NaOH}), \text { freeze-drying } \\
100 \text { eq., freeze-drying } \\
500 \text { eq., freeze-drying } \\
500 \text { eq., evaporation }\end{array}$ & $\begin{array}{l}32: 68 \\
\text { (incomplete) } \\
54: 46 \\
16: 84\end{array}$ & Deoxycytidine & $\begin{array}{l}500 \text { eq., freeze-drying } \\
500 \text { eq., evaporation }\end{array}$ & $\begin{array}{l}40: 60 \\
33: 67\end{array}$ \\
\hline
\end{tabular}

b) Electropherograms CE-MS analysis:
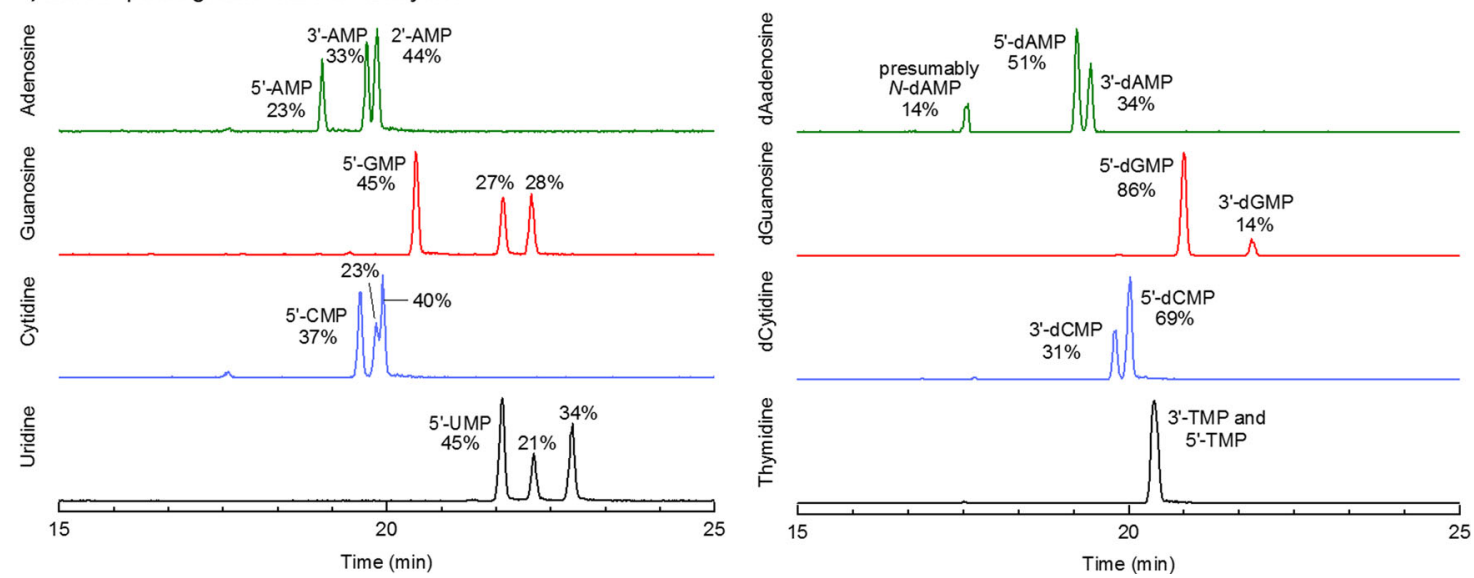

Fig. 6 Phosphorylation of nucleosides by $\mathbf{u P}_{\mathbf{4}} \mathbf{( 2 )}$ and electropherograms of the CE-MS analysis. a Conditions and phosphorylation rates for the reaction of nucleosides with $\mathrm{uP}_{4}$. If the $\mathrm{pH}$ of the nucleophile solution was adjusted, the applied base is indicated in brackets. Phosphorylation rates were calculated without consideration of the phosphoramidate by-product arising from the reaction of DBU with $\mathrm{uP}_{4}$. $\mathbf{b}$ Electropherograms of the CE-MS analysis of the product distribution. The positional isomers were determined by spiking experiments.

we additionally detected a phosphoramidate arising from the reaction of $\mathrm{DBU}$ - which was present due to the deprotection conditions - with $\mathrm{uP}_{4}$. This side-reaction was avoided using polymer-bound DBU for the deprotection, affording $\mathrm{DBU}$ free $\mathrm{uP}_{4}$ in $81 \%$ purity (see Supplementary Fig. 15). Interestingly, $\mathrm{uP}_{4} 2$ was found to be less stable in the absence of DBU. Thus, further experiments were performed with DBU in solution due to the better repeatability. For different amino acids, the primary or secondary amine and - if present - the alcohol or thiol moiety were phosphorylated (Supplementary Fig. 15). For glycine, only $8 \%$ phosphorylation of the amine was observed at $\mathrm{pH} 8.8$ but the adjustment to $\mathrm{pH} 13.0$ increased the phosphorylation to $66 \%$, in accordance with the longer half-life of $\mathrm{uP}_{4}$ at higher $\mathrm{pH}$ (see Fig. 4a). Although it is unclear whether this $\mathrm{pH}$ condition is relevant to prebiotic chemistry ${ }^{60}$, the result still shows a general reactivity trend. Freeze-drying experiments increased the phosphorylation of glycine to its phosphoramidate to $52 \%$ at a $\mathrm{pH}$ of ca. 9.

For all canonical (deoxy)nucleosides, even 10 eq. were sufficient to detect phosphorylated nucleosides by CE-MS after freeze-drying. For full consumption of $\mathrm{uP}_{4} 2$ in one single freeze-drying experiment, 500 eq. were necessary. These conditions allowed phosphorylation of up to $54 \%$, whereas evaporation of solvent at room temperature resulted in $33 \%$ nucleoside phosphorylation. The product distribution was analysed by CE-MS, and spiking experiments revealed product identities (Fig. 6b). We found phosphorylation in the $5^{\prime}$ - and also $2^{\prime}$ - and $3^{\prime}$-positions. To rule out phosphorylation arising from inorganic mono- and triphosphate, these compounds were lyophilised with 3000 eq. uridine, leading to no phosphorylation. Ultraphosphate $\mathbf{2}$ as a model substrate - and by extension other branched polyP-may thus have served as phosphate donors in prebiotic chemistry.

Life relies on condensed phosphates, but ultraphosphates as a fundamental type and true constitutional isomers of the linear polyP remained unstudied. In this study, we disclose the synthesis of defined monodisperse ultraphosphates containing zero to three modifications. For those short-chain ultraphosphates, we found significant hydrolytic stability expressed in half-lives up to days, which calls the antibranching-rule into question. We provide evidence for the interaction of an enzyme with ultraphosphates and describe the phosphate walk, which linearises branched phosphates. Ultraphosphate was applied as a phosphorylating reagent for nucleophiles such as amino acids and nucleosides with implications for prebiotic chemistry. With synthetic access to this class of molecules, the chemistry-and potential biology - of the branched phosphates can finally be studied.

\section{Methods}

General procedure for the synthesis of ultraphosphates. In all, 3.0 eq. of a monophosphate TBA salt and 3.0 eq. of an activator (ETT or DCI) were coevaporated using MeCN (3x) and afterwards dissolved in DMF. 1.0 eq. of $\mathrm{P}\left(\mathrm{NEt}_{2}\right)_{3}$ was added and stirred for $10 \mathrm{~min}$. Upon completion of the coupling, $1.5 \mathrm{eq}$. $m$ CPBA $(77 \%)$ was added at $0{ }^{\circ} \mathrm{C}$ and stirred for $10 \mathrm{~min}$. The product was precipitated using $\mathrm{Et}_{2} \mathrm{O}$, the suspension centrifuged and the pellet washed with $\mathrm{Et}_{2} \mathrm{O}$. Drying in vacuo gave the crude product as a mixed TBA/diethylammonium salt. The ultraphosphate was purified by AIEX chromatography (Q Sepharose ${ }^{\circledast}$ Fast 
Flow) or using a PuriFlash Column $(30 \mu \mathrm{C} 18 \mathrm{AQ}$; water, MeCN gradient (0-45\%), $10 \%$ TEAA (100 mm, pH 7.0)).

\section{General procedure for the salt exchange of ultraphosphates to [PPN] salts} The crude ultraphosphate is either purified by anion exchange chromatography using Q Sepharose ${ }^{\circledast}$ Fast Flow and a $\mathrm{NaCl}(1 \mathrm{M})$ gradient or by using a PuriFlash Column $(30 \mu \mathrm{C} 18 \mathrm{AQ}$; water, MeCN gradient (0-45\%), 10\% TEAA (100 mM, pH 7.0)). Fractions containing ultraphosphate were analysed for their concentration by addition of a defined volume of a $\mathrm{PMe}_{4} B r$ solution in $\mathrm{D}_{2} \mathrm{O}(1 \mathrm{mg} / \mathrm{ml})$ and ${ }^{31} \mathrm{P}\left\{{ }^{1} \mathrm{H}\right\}$ NMR. Fractions were combined and heated to $55^{\circ} \mathrm{C}$. [PPN]-Cl (2-3 eq.) was dissolved in $\mathrm{H}_{2} \mathrm{O}$ (yielding $\sim 2-5 \mathrm{~mm}$ solution) at $55^{\circ} \mathrm{C}$ and added to the ultraphosphate solution. The precipitate was collected by centrifugation and washed with warm water $\left(\sim 55^{\circ} \mathrm{C}\right)$. The residue was dissolved in acetone, dried over $\mathrm{Na}_{2} \mathrm{SO}_{4}$ and the solvent removed in vacuo.

\section{Data availability}

All data supporting the findings of this study are available in the article and Supplementary Information file or from the corresponding author upon reasonable request. The X-ray crystallography data have been deposited at the Cambridge Crystallographic Data Centre (CCDC), under accession number CCDC: 2032762. These data can be obtained free of charge from The Cambridge Crystallographic Data Centre via www.ccdc.cam.ac.uk/data_request/cif.

Received: 8 April 2021; Accepted: 18 August 2021; Published online: 10 September 2021

\section{References}

1. Rao, N. N., Gómez-García, M. R. \& Kornberg, A. Inorganic polyphosphate: essential for growth and survival. Annu. Rev. Biochem. 78, 605-647 (2009).

2. Kashemirov, B. A., Błażewska, K. Justyna, K. \& McKenna, C. E. 42.16 .4 Phosphoric Acid and its Derivatives. In Science of Synthesis: Knowledge Updates 2021/1, edited by X. Jiang, et al. 1st ed. (Thieme Verlag 2021).

3. Christ, J. J., Willbold, S. \& Blank, L. M. Methods for the analysis of polyphosphate in the life sciences. Anal. Chem. 92, 4167-4176 (2020).

4. Achbergerová, L. \& Nahálka, J. Polyphosphate - an ancient energy source and active metabolic regulator. Microb. Cell Fact. 10, 63-76 (2011).

5. Xie, L. \& Jakob, U. Inorganic polyphosphate, a multifunctional polyanionic protein scaffold. J. Biol. Chem. 294, 2180-2190 (2019).

6. Thilo, E. \& Sonntag, A. Zur Chemie der kondensierten Phosphate und Arsenate. Über Bildung und Eigenschaften vernetzter Phosphate des Natriums. Z. Anorg. Allg. Chem. 291, 186-204 (1957).

7. Van Wazer, J. R. Phosphorus and Its Compounds, Vol. I: Chemistry (Interscience Publishers, Inc., New York, 1958).

8. Kornberg, A., Kornberg, S. R. \& Simms, E. S. Metaphosphate synthesis by an enzyme from Echerichia Coli. Biochim. Biophys. Acta 20, 215-227 (1956).

9. Mandala, V. S. et al. Bacterial phosphate granules contain cyclic polyphosphates. Evidence from ${ }^{31} \mathrm{P}$ solid-state NMR. J. Am. Chem. Soc. 142, 18407-18421 (2020).

10. Schröder, H. C. \& Müller, W. E. G. Inorganic polyphosphates. Biochemistry, Biology, Biotechnology (Springer, Berlin, Heidelberg, 1999).

11. Averbuch-Pouchot, M. T. \& Durif, A. Crystal chemistry of ultraphosphates. $Z$. Kristallogr. 201, 69-92 (1992).

12. Van Wazer, J. R. Structure and properties of the condensed phosphates. II. A theory of the molecular structure of sodium phosphate glasses. J. Am. Chem. Soc. 72, 644-647 (1950).

13. Van Wazer, J. R. Principles of phosphorus chemistry. I. Some generalities concerning multiple bonding. J. Am. Chem. Soc. 78, 5709-5715 (1956).

14. Van Wazer, J. R. \& Holst, K. A. Structure and properties of the condensed phosphates. I. Some general considerations about phosphoric acids. J. Am. Chem. Soc. 72, 639-644 (1950).

15. Van Wazer, J. R. \& Griffith, E. J. Structure and properties of the condensed phosphates. X. General structural theory. J. Am. Chem. Soc. 77, 6140-6144 (1955).

16. Stachel, D. \& Olbertz, A. Structure building principles in crystalline ultraphosphates. Phos. Res. Bull. 10, 70-75 (1999).

17. Hoppe, U., Walter, G., Stachel, D., Barz, A. \& Hannon, A. C. Neutron and $\mathrm{X}$-ray diffraction study on the structure of ultraphosphate glasses. $Z$. Naturforsch. 52, 259-269 (1997).

18. Griffith, E. J. Factors Influencing the Chain Lengths of Inorganic Polyphosphates. In Phosphorus Chemistry. Developments in American science, edited by E. N. Walsh, E. J. Griffith, R. W. Parry \& L. D. Quin (American Chemical Society, Washington, D.C., 1992), Vol. 486, pp. 86-101.

19. Olbertz, A. \& Stachel, D. Structure models for crystalline ultraphosphates selection and diversity. Phos. Res. Bull. 12, 191-202 (2001).
20. Strauss, U. P. \& Treitler, T. L. Chain branching in glassy polyphosphates. Dependence on the $\mathrm{Na} / \mathrm{P}$ ratio and rate of degradation at $25^{\circ}$. J. Am. Chem. Soc. 77, 1473-1476 (1955).

21. Gill, J. B. \& Riaz, S. A. Some investigations concerning the structure of ultraphosphates. J. Chem. Soc. A 5, 843-849 (1969).

22. Strauss, U. P. \& Treitler, T. L. Degradation of polyphosphates in solution. I. Kinetics and mechanism of the hydrolysis at branching points in polyphosphate chains. J. Am. Chem. Soc. 78, 3553-3557 (1956).

23. Brow, R. K. Review: the structure of simple phosphate glasses. J. Non-Cryst. Solids 263-264, 1-28 (2000).

24. Glonek, T., Kleps, R. A., Van Wazer, J. R. \& Myers, T. C. Carbodiimideintermediated esterification of the inorganic phosphates and the effect of tertiary amine base. Bioinorg. Chem. 5, 283-310 (1976).

25. Glonek, T., Van Wazer, J. R. \& Myers, T. C. ${ }^{31} \mathrm{P}$ nuclear magnetic resonance studies of phosphate condensations with trichloroacetonitrile. II. Condensation and hydration in the ultraphosphate region. Bioinorg. Chem. 1, 23-34 (1971).

26. Myers, T. C., Glonek, T., Han, P. Z. \& Van Wazer, J. R. Evidence for a small ultraphosphate molecule in solution. J. Am. Chem. Soc. 92, 7214-7216 (1970).

27. Glonek, T., Van Wazer, J. R., Mudgett, M. \& Myers, T. C. Cyclic metaphosphates from hydrolysis of the products from phosphoric acid condensation with carbodiimides. Inorg. Chem. 11, 567-570 (1972).

28. Glonek, T., Van Wazer, J. R., Kleps, R. A. \& Myers, T. C. Cyclic phosphates with substitution or with conjoined or fused rings. Inorg. Chem. 13, $2337-2345$ (1974).

29. Mohamady, S. \& Taylor, S. D. Synthesis of nucleoside tetraphosphates and dinucleoside pentaphosphates via activation of cyclic trimetaphosphate. Org. Lett. 15, 2612-2615 (2013).

30. Mohsen, M. G., Ji, D. \& Kool, E. T. Polymerase synthesis of four-base DNA from two stable dimeric nucleotides. Nucleic Acids Res. 47, 9495-9501 (2019).

31. Azevedo, C. et al. Screening a protein array with synthetic biotinylated inorganic polyphosphate to define the human PolyP-ome. ACS Chem. Biol. 13, 1958-1963 (2018).

32. Singh, J. et al. A phosphoramidite analogue of cyclotriphosphate enables iterative polyphosphorylations. Angew. Chem. Int. Ed. 58, 3928-3933 (2019).

33. Shepard, S. M. \& Cummins, C. C. Functionalization of intact trimetaphosphate. A triphosphorylating reagent for $\mathrm{C}, \mathrm{N}$, and $\mathrm{O}$ nucleophiles. J. Am. Chem. Soc. 141, 1852-1856 (2019).

34. Jiang, Y. et al. Dihydrogen tetrametaphosphate, $\left[\mathrm{P}_{4} \mathrm{O}_{12} \mathrm{H}_{2}\right]^{2-}$. Synthesis, solubilization in organic media, preparation of its anhydride $\left[\mathrm{P}_{4} \mathrm{O}_{11}\right]^{2-}$ and acidic methyl ester, and conversion to tetrametaphosphate metal complexes via potonolysis. J. Am. Chem. Soc. 136, 11894-11897 (2014).

35. Shepard, S. M., Windsor, I. W., Raines, R. T. \& Cummins, C. C. Nucleoside tetra- and pentaphosphates prepared using a tetraphosphorylation reagent are potent inhibitors of ribonuclease A. J. Am. Chem. Soc. 141, 18400-18404 (2019).

36. Bezold, D., Dürr, T., Singh, J. \& Jessen, H. J. Cyclotriphosphate: a brief history, recent developments, and perspectives in synthesis. Chem. Eur. J. 26, 2298-2308 (2020).

37. Hofer, A. et al. Chemoselective dimerization of phosphates. Org. Lett. 18, 3222-3225 (2016)

38. Kern, J. C. et al. Discovery of pyrophosphate diesters as tunable, soluble, and bioorthogonal linkers for site-specific antibody-drug conjugates. J. Am. Chem. Soc. 138, 1430-1445 (2016).

39. Martinsen, A. \& Songstad, J. Preparation and properties of some bis(triphenylphosphine)iminium salts, $\left[\left(\mathrm{Ph}_{3} \mathrm{P}\right)_{2} \mathrm{~N}\right] \mathrm{X}$. Acta Chem. Scand. 31, 645-650 (1977)

40. Smith, S. A. \& Morrissey, J. H. Sensitive fluorescence detection of polyphosphate in polyacrylamide gels using 4',6-diamidino-2-phenylindol. Electrophoresis 28, 3461-3465 (2007).

41. Glonek, T. Did cyclic metaphosphates have a role in the origin of life? Orig. Life Evol. B. 51, 1-60 (2021).

42. Inouye, M. Effect of acetone on alkaline phosphatase activity. J. Biochem. 54, 138-145 (1963).

43. Johnny Cash. I Walk the Line (1956).

44. Kowada, Y., Adachi, H. \& Minami, T. Electronic states and chemical bonding in phosphate glasses. J. Phys. Chem. 97, 8989-8992 (1993).

45. Florián, J. \& Warshel, A. Phosphate ester hydrolysis in aqueous solution: associative versus dissociative mechanisms. J. Phys. Chem. B 102, 719-734 (1998).

46. Westheimer, F. H. The hydrolysis of phosphate esters. Pure Appl. Chem. 49, 1059-1067 (1977).

47. Diez-Castellnou, M., Martinez, A. \& Mancin, F. Phosphate ester hydrolysis: the path from mechanistic investigation to the realization of artificial enzymes. Adv. Phys. Org. Chem. 51, 129-186 (2017).

48. Abramson, R. \& Baldridge, K. K. Defined-sector explicit solvent in the continuum model approach for computational prediction of $\mathrm{p} K_{\mathrm{a}}$. Mol. Phys. 110, 2401-2412 (2012). 
49. Abramson, R. A. \& Baldridge, K. K. Defined-sector explicit solvent in continuum cluster model for computational prediction of pka: consideration of secondary functionality and higher degree of solvation. J. Chem. Theory Comput. 9, 1027-1035 (2013).

50. Kirby, A. J. Effective molarities for intramolceluar reactions. Adv. Phys. Org. Chem. 17, 183-278 (1980).

51. Mazor, M. H., Wong, C. F., McCammon, J. A., Deutch, J. M. \& Whitesides, G. Effective molarity in diffusion-controlled reactions. J. Phys. Chem. 94, 3807-3812 (1990).

52. Gull, M. Prebiotic phosphorylation reactions on the early earth. Challenges 5, 193-212 (2014).

53. Fernández-García, C., Coggins, A. J. \& Powner, M. W. A chemist's perspective on the role of phosphorus at the origins of life. Life 7, 31-53 (2017).

54. Kim, H.-J. \& Benner, S. A. Prebiotic stereoselective synthesis of purine and noncanonical pyrimidine nucleotide from nucleobases and phosphorylated carbohydrates. Proc. Natl Acad. Sci. USA 114, 11315-11320 (2017).

55. Kim, H.-J. \& Benner, S. A. Abiotic synthesis of nucleoside $5^{\prime}$-triphosphates with nickel borate and cyclic trimetaphosphate (CTMP). Astrobiology 21, 298-306 (2021).

56. Yamagata, Y., Kojima, H., Ejiri, K. \& Inomata, K. AMP synthesis in aqueous solution of adenosine and phosphorus pentoxide. Orig. Life Evol. Biosph. 12, 333-337 (1982).

57. Yamagata, Y., Watanabe, H., Saitoh, M. \& Namba, T. Volcanic production of polyphosphates and its relevance to prebiotic evolution. Nature 352, 516-519 (1991).

58. Griffith, E. J. Phosphorus, a key to life on the primitive earth. Orig. Life 8, 71-85 (1977).

59. Thilo, E. \& Wieker, W. Zum chemischen Strukturbeweis der hexagonalen, leichtflüchtigen Modifikation des Phosphor(V)-oxydes. III. Die Hydrolyse des Phosphor(V)-oxydes. Z. Anorg. Allg. Chem. 277, 27-36 (1954).

60. Ashe, K. et al. Selective prebiotic synthesis of phosphoroaminonitriles and aminothioamides in neutral water. Commun. Chem. 2, 23 (2019).

61. Albrand, K.-R., Attig, R., Fenner, J., Jeser, J. P. \& Mootz, D. Crystal structure of the laser material $\mathrm{NdP}_{5} \mathrm{O}_{14}$. Mat. Res. Bull. 9, 129-140 (1974).

62. Seel, F., Busch, G. \& Klein, N. Die Umsetzung des trimethylphosphats mit hexamethylphosphorsauretriamid -eine rationelle synthese eines cyclotriphosphats. Z. Anorg. Allg. Chem. 516, 177-180 (1984).

63. Burcar, B. et al. Darwin's warm little pond: a one-pot reaction for prebiotic phosphorylation and the mobilization of phosphate from minerals in a ureabased solvent. Angew. Chem. Int. Ed. 55, 13249-13253 (2016).

\section{Acknowledgements}

We thank Dr. Manfred Keller from MagRes of the University of Freiburg for the kind support and a significant amount of time for NMR spectroscopy. We thank Christoph Warth for HRMS measurements, Wiebke Unkrig and Stefan Meier for Raman measurements and Daniel Kratzert and Boumahdi Benkmil for support in X-ray crystallography. We acknowledge helpful discussions with Scott M. Shepard and Christopher C. Cummins regarding crystallisation conditions. Moreover, we thank Thomas Haas, Jyoti Singh and Laura Mayer for their insightful comments. The authors gratefully acknowledge financial support from the VW Foundation (Experiment!AZ92270), and the
Human Frontier Science Program HFSP (RGP0025/2016). This study was supported by the Deutsche Forschungsgemeinschaft (DFG, German Research Foundation) under Germany's Excellence Strategy (EXC-2193/1-390951807) and a scholarship grant from Cusanuswerk

\section{Author contributions}

T.D-M. and H.J.J. conceived the research project and wrote the manuscript. T.D. prepared the samples and applied them in follow-up studies. N.S. and A.H. gave input on the synthetic procedure. D.Q. developed the CE-MS method. D.Q. and M.H. analysed samples using CE-MS and supported data analysis. V.B.E. analysed samples using PAGE. A.M. provided polyP extracts from yeast. J.S.S. and K.K.B. performed DFT calculations

\section{Funding}

Open Access funding enabled and organized by Projekt DEAL.

\section{Competing interests}

The authors declare no competing interests.

\section{Additional information}

Supplementary information The online version contains supplementary material available at https://doi.org/10.1038/s41467-021-25668-3.

Correspondence and requests for materials should be addressed to Henning J. Jessen.

Peer review information Nature Communications thanks Lars Blank, Charles McKenna and the anonymous reviewer(s) for their contribution to the peer review of this work. Peer reviewer reports are available.

Reprints and permission information is available at http://www.nature.com/reprints

Publisher's note Springer Nature remains neutral with regard to jurisdictional claims in published maps and institutional affiliations.

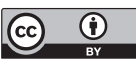

Open Access This article is licensed under a Creative Commons Attribution 4.0 International License, which permits use, sharing, adaptation, distribution and reproduction in any medium or format, as long as you give appropriate credit to the original author(s) and the source, provide a link to the Creative Commons license, and indicate if changes were made. The images or other third party material in this article are included in the article's Creative Commons license, unless indicated otherwise in a credit line to the material. If material is not included in the article's Creative Commons license and your intended use is not permitted by statutory regulation or exceeds the permitted use, you will need to obtain permission directly from the copyright holder. To view a copy of this license, visit http://creativecommons.org/ licenses/by/4.0/

(C) The Author(s) 2021 